\title{
Using Conflict Analysis Method to Analyze Crimea Crisis Between Russia and Ukraine
}

\author{
Xiaojia Jiang ${ }^{1 *}$, Lei Yang ${ }^{1}$, Chaolu Ma ${ }^{2}$, Mingfei $\mathrm{Wu}^{1}$, Feng Liu ${ }^{1}$, \\ Yuhui Wei ${ }^{1}$, Xiaoli $\mathrm{Xu}^{3}$ \\ ${ }^{1}$ Institute of NBC Defence, Beijing 102205, China \\ ${ }^{2}$ Institute of NBC Protection, Beijing, 100144, China \\ ${ }^{3}$ Taizhou University, Taizhou, 225300, China \\ *jxj1321@163.com
}

Keywords: conflict analysis method, Crimea crisis.

Abstract. In view of the growing complexity of Crimea Crisis between Russia and Crimea, on the basis of analyzing the origin and weighing all the factors, the use of conflict analysis method could be taken to analyze the strategies that may be taken by both sides and boldly forecast the trends and outcomes. Meanwhile, it also has certain reference value for strategy game of the similar conflicts.

\section{Introduction}

Crimea public voting to join in Russia, no doubt, is a major strategic and historic event to the entire international community. It is bound to be a long-term strategy game for Ukraine, Europe and the United States or Russia. Any mistake or delay in game will have unpredictable repercussions of political, economic and military, resulting in undesirable results. In order to get the outcome in their favor, the players can make use of conflict analysis method to achieve a supporting role in establishing a major strategic policy.

\section{Basic Theory of the Conflict Analysis Method}

A complete conflict analysis should consist of conflict mode establishment and conflict stability analysis. The role of the former is to systematically express all the information related to the conflict that analysts have obtained, in order to grasp the whole picture of the conflict; the role of the latter is to predict the possible outcome of the conflict based on a conflict model, in order to provide the basis for decisions.

Conflict Sorting Mode. For a moment of conflict situations, all previous information about this conflict can be abstracted according to the following three aspects, which constitutes a conflict sorting mode:

The Players. The main decision makers of the parties to the conflict.

The Scheme. The action that might be taken by the players in the conflict. A set of solutions selected by the players constitutes a strategy. The game status that each player chooses a strategy is an outcome of the conflict.

Sorting Each Possible Outcome of the Game According to Their Values. There are several sorting corresponding to the number of the players.

\section{Stability Analysis.}

Stability Concepts. The actual purpose of stability analysis is to determine the equilibrium solution of the conflict. As for the conflict consisting of two players, if a outcome of the conflict is stable for the both players, this outcome is an equilibrium solution of the conflict. The basis of stability concept is the reasonable assumptions that the players will surely choose a more favorable solution for themselves from two solutions which can cause different outcomes. Thus, if the players may get a more negative outcome for themselves by changing their strategies, the outcome is stable for the players. Clearly, 
equilibrium solution is the most likely outcome of the conflict, because both sides believe that it would be impossible to get a more satisfactory outcome than this ending.

Stability Conditions. According to stability concepts to judge the stability, you need to determine which outcome of the conflict can be improved unilaterally for each of the players. When the other players didn't change strategies, it means that the player who has changed strategy can convert the original outcome into a new ending which will be more favorable for himself. Unilateral improvement can be abbreviated as UI in this article.

Based on the players' preference to the outcome of conflict and UI of each possible outcome, it is not difficult to apply the basic concepts of logistics and set theory to determine the stability of any possible outcome to the particular player. In a simple conflict consisting of two players, the analyzing steps of the outcome q's stability to the player A will be shown in Figure 1.

(1) Reasonable outcome: If B does not change strategy, as A does no unilateral improvement from $\mathrm{q}$, the strategy adopted by A is the best. Therefore, a reasonable outcome will be stable. Denoted by $\mathrm{r}$.

(2) Unstable outcomes: A does at least one unilateral improvement from q, while the B cannot make $\mathrm{A}$ in a more adverse position than the original by any unilateral improvement. Denoted by $\mathrm{u}$.

(3) Synchronously restricted outcome: If $\mathrm{q}$ is not stable for both A and B, it can cause a more adverse outcome for one or both when A and B change strategies at the same time from $\mathrm{q}$. This will restrict one or both from doing further improvement. Therefore, this outcome is stable. Recorded as u'. Test of synchronously restricted outcome can be calculated as follows:

The outcome q' that both A and B simultaneously do unilateral improvement from $q=$ (the outcome that A does unilateral improvement from $q)+($ the outcome that $B$ does unilateral improvement from $q$ ) $-\mathrm{q}$.

If $\mathrm{q}^{\prime}$ is more negative than q for A or B, q' is a synchronously restricted outcome.

(4) Subsequently restricted outcome: B can do unilateral improvement in response to A's any unilateral improvement from q, it will make the new outcome be more adverse than the original for A. B's unilateral improvement is called trusted resistance. Obviously, subsequently restricted outcome is stable for A. Denoted by s.

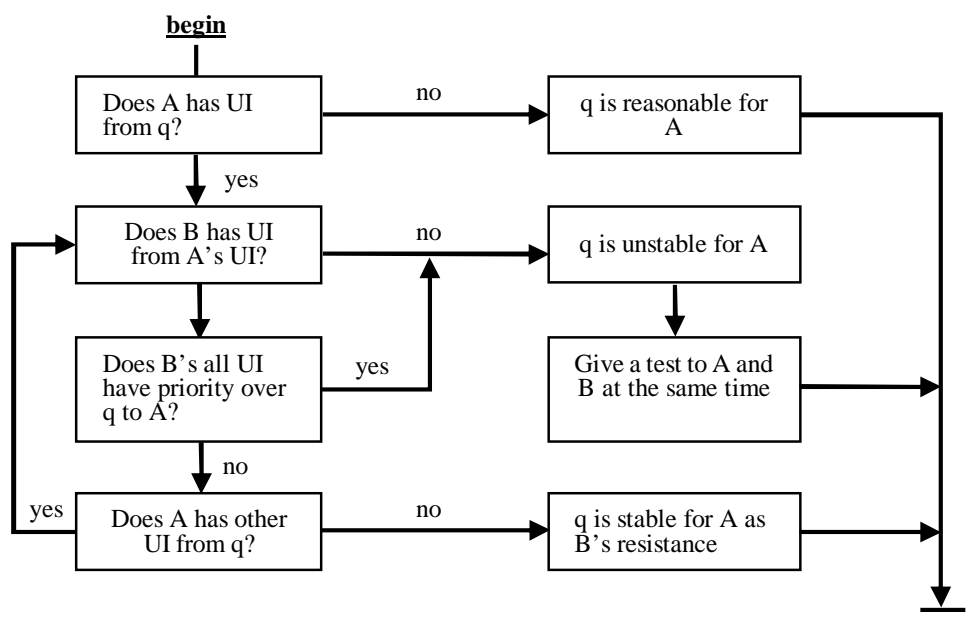

Fig.1: UI - Unilateral Improvements

\section{Applying Conflict Analysis Method to Crimea Crisis}

\section{Establish Conflict Mode.}

The Players. On Crimea Crisis issue, Russia is clearly one of the players, but another player is special. Ukraine who has no ability to preserve itself is the weakest power in the center of the crisis. Additionally, for Europe and the United States, controlling Crimea is equivalent to embedding a winning wedge in controlling Eurasia. Europe and the United States cannot sit idly by. Therefore, here we have Ukraine who is supported by Europe and the United States as the player. 
Possible Actions. Russia's actions may be taken as the following three kinds:

Firstly, do not take any military action, but only through diplomatic negotiations to put pressure on Ukraine. This can save Crimea Crisis from escalation.

Secondly, seizing Crimea (which may also include the south-eastern part of Ukraine) in a conventional attack. This will be accused of aggression against Ukraine.

Lastly, in the case of sending troop without damaging the allies, support Yanukovych as an agent and serve Crimean peninsula and the eastern Ukraine as Yanukovich's counter positions.

Possible actions of Ukraine may be three kinds:

Firstly. Insist Crimea is an inalienable part of Ukraine and swear to defend.

Secondly. Give up the ownership of Crimea under Russian military pressure and admit the independence of Crimea.

Lastly. Escalate the crisis, such as attacks on the Russian Black Sea Fleet which stationed in Crimea.

Information concerning the above issues can be expressed in the format of Table 1. The selected scheme by the players is denoted by 1 in the table, conversely denoted by 0 . Russian player's two schemes constitute four kinds of strategy, and the Ukraine player's two schemes only constitute three kinds of strategy (because it is unjustifiable and impossible to take the strategy that consists of both giving up and escalating simultaneously). Each outcome is denoted by 4-digit column which consists of 0 and 1.Then, convert column into decimal numeral through digital equivalence between decimal and binary digital in order to facilitate the stability analysis.

Table 1: Schemes and strategies

\begin{tabular}{|c|c|c|c|c|c|c|c|c|c|c|c|c|c|}
\hline $\begin{array}{l}\text { The } \\
\text { plavers }\end{array}$ & $\begin{array}{l}\text { Possible } \\
\text { Schemes }\end{array}$ & \multicolumn{12}{|c|}{ Strategies } \\
\hline \multirow{2}{*}{ Russia } & Seize & 0 & 1 & 0 & 1 & 0 & 1 & 0 & 1 & 0 & 1 & 0 & 1 \\
\hline & Support & 0 & 0 & 1 & 1 & 0 & 0 & 1 & 1 & 0 & 0 & 1 & 1 \\
\hline \multirow{2}{*}{ Ukraine } & Give up & 0 & 0 & 0 & 0 & 1 & 1 & 1 & 1 & 0 & 0 & 0 & 0 \\
\hline & Escalate & 0 & 0 & 0 & 0 & 0 & 0 & 0 & 0 & 1 & 1 & 1 & 1 \\
\hline \multicolumn{2}{|c|}{$\begin{array}{l}\text { Conclusions in } \\
\text { decimal } \\
\text { representation }\end{array}$} & 0 & 1 & 2 & 3 & 4 & 5 & 6 & 7 & 8 & 9 & 10 & 11 \\
\hline
\end{tabular}

Outcome Sorting. Outcome sorting often requires the players to get the other information reliably and gives a detailed qualitative and quantitative analysis. Here, we assume that the players in the conflict understand each other about preference for the outcome.

On Crimea crisis issue, on the one hand, Russia determines to get the ownership of Crimea, and on the other hand, Russia has been full of misgiving due to the difficulties at home and abroad. Therefore, Russia most wants Ukraine to give up the ownership of Crimea rather than makes the crisis escalated. If Ukraine gives up the ownership of Crimea, Russia wants its military operations to be small scale as far as possible. If Ukraine makes the crisis escalated, Russia will take the most aggressive action. If Ukraine takes actions which not only defend the territorial integrity of Ukraine but also don't escalate the crisis, Russia will take some actions to make Ukraine give up the ownership of Crimea, but not unnecessarily anger Ukraine who is supported by Europe and the United States. On the basis of the analysis, we can deduce Russian preference sequence for Crimea crisis. As shown in Table 2.

Table 2: Russian preference sequence for Crimea crisis

\begin{tabular}{|c|c|c|c|c|c|c|c|c|c|c|c|c|c|}
\hline $\begin{array}{l}\text { The } \\
\text { plavers }\end{array}$ & $\begin{array}{l}\text { Possible } \\
\text { Schemes }\end{array}$ & \multicolumn{12}{|c|}{ Strategies } \\
\hline \multirow{2}{*}{ Russia } & Seize & 0 & 0 & 1 & 1 & 0 & 1 & 1 & 0 & 1 & 1 & 0 & 0 \\
\hline & Support & 0 & 1 & 0 & 1 & 1 & 0 & 1 & 0 & 1 & 0 & 1 & 0 \\
\hline \multirow{2}{*}{ Ukraine } & Give up & 1 & 1 & 1 & 1 & 0 & 0 & 0 & 0 & 0 & 0 & 0 & 0 \\
\hline & Escalate & 0 & 0 & 0 & 0 & 0 & 0 & 0 & 0 & 1 & 1 & 1 & 1 \\
\hline \multicolumn{2}{|c|}{$\begin{array}{l}\text { Conclusions in } \\
\text { decimal representation }\end{array}$} & 4 & 6 & 5 & 7 & 2 & 1 & 3 & 0 & 11 & 9 & 10 & 8 \\
\hline
\end{tabular}


Ukraine also expects to avoid the crisis escalated. If the crisis is escalated, Ukraine expects that Russia also has a corresponding act of aggression in order to avoid international isolation. Therefore (0001) is Ukrainian most undesirable results. If the crisis isn't escalated, Ukraine expects that Russia does not occupy Crimea and supports no agent. If Russia takes any military action, Ukraine will have to give up the ownership of Crimea. However , if Russia does not take military action, Ukraine is willing to safeguard national unity and defend territorial integrity. Therefore, Ukrainian preference sequence for Crimea Crisis is shown in Table 3.

Table 3: Ukrainian preference sequence for Crimea crisis

\begin{tabular}{|c|c|c|c|c|c|c|c|c|c|c|c|c|c|}
\hline The & Possible & \multicolumn{12}{|c|}{ Strategies } \\
\hline \multirow{2}{*}{ Russia } & Seize & 0 & 0 & 0 & 0 & 1 & 1 & 1 & 1 & 1 & 1 & 0 & 0 \\
\hline & Support & 0 & 0 & 1 & 1 & 0 & 0 & 1 & 1 & 1 & 0 & 1 & 0 \\
\hline \multirow{2}{*}{ Ukraine } & Give up & 0 & 1 & 1 & 0 & 1 & 0 & 1 & 0 & 0 & 0 & 0 & 0 \\
\hline & Escalate & 0 & 0 & 0 & 0 & 0 & 0 & 0 & 0 & 1 & 1 & 1 & 1 \\
\hline \multicolumn{2}{|c|}{$\begin{array}{l}\text { Conclusions in decimal } \\
\text { representation }\end{array}$} & 0 & 4 & 6 & 2 & 5 & 1 & 7 & 3 & 11 & 9 & 10 & 8 \\
\hline
\end{tabular}

Stability Analysis of Conflict. According to the above steps, the result of stability analysis of Crimea Crisis is shown in Table 4. The table shows:

Table 4: Stability analysis of Crimea crisis

\begin{tabular}{|c|c|c|c|c|c|c|c|c|c|c|c|c|c|}
\hline \multirow{5}{*}{ Russia } & $\begin{array}{c}\text { Stability of the } \\
\text { players }\end{array}$ & $\mathrm{r}$ & $\mathrm{s}$ & $\mathrm{u}$ & $\mathrm{u}$ & $\mathrm{r}$ & $\mathrm{u}$ & $\mathrm{u}$ & $\mathrm{u}$ & $\mathrm{r}$ & $\mathrm{u}$ & $\mathrm{u}$ & $\mathrm{u}$ \\
\hline & $\begin{array}{l}\text { Preference } \\
\text { sequence }\end{array}$ & 4 & 6 & 5 & 7 & 2 & 1 & 3 & 0 & 11 & 9 & 10 & 8 \\
\hline & \multirow{3}{*}{$\begin{array}{c}\text { Unilateral } \\
\text { improvements }\end{array}$} & & 4 & 4 & 4 & & 2 & 2 & 2 & & 11 & 11 & 11 \\
\hline & & & & 6 & 6 & & & 1 & 1 & & & 9 & 9 \\
\hline & & & & & 5 & & & & 3 & & & & 10 \\
\hline \multirow{4}{*}{ Ukraine } & $\begin{array}{c}\text { Stability of the } \\
\text { players }\end{array}$ & $\mathrm{r}$ & $\mathrm{s}$ & $\mathrm{r}$ & $\mathrm{u}$ & $\mathrm{r}$ & $\mathrm{u}$ & $\mathrm{r}$ & $\mathrm{u}$ & $\mathrm{u}$ & $\mathrm{u}$ & $\mathrm{u}$ & $\mathrm{u}$ \\
\hline & $\begin{array}{l}\text { Preference } \\
\text { sequence }\end{array}$ & 0 & 4 & 6 & 2 & 5 & 1 & 7 & 3 & 11 & 9 & 10 & 8 \\
\hline & \multirow{2}{*}{$\begin{array}{c}\text { Unilateral } \\
\text { improvements }\end{array}$} & & 0 & & 6 & & 5 & & 7 & 7 & 5 & 6 & 0 \\
\hline & & & & & & & & & & 3 & 1 & 2 & 4 \\
\hline \multirow{2}{*}{ Synthesis } & Outcome No. & 1 & 2 & 3 & 4 & 5 & 6 & 7 & 8 & 9 & 10 & 11 & 0 \\
\hline & $\begin{array}{l}\text { Equilibrium } \\
\text { solutions }\end{array}$ & $\mathrm{X}$ & $\mathrm{X}$ & $\mathrm{X}$ & $\mathrm{E}$ & $\mathrm{X}$ & $\mathrm{E}$ & $\mathrm{X}$ & $\mathrm{X}$ & $\mathrm{X}$ & $\mathrm{X}$ & $\mathrm{X}$ & $\mathrm{X}$ \\
\hline
\end{tabular}

Outcome 4,2,11 are reasonable for Russia, and outcome 0,6,5,7 are reasonable for Ukraine.

Outcome 6 is subsequently restricted outcome for Russia, so it is stable. In fact, outcome 6 may be unilaterally improved to outcome 4 . However, according to Ukrainian preference sequence, Ukraine can unilaterally improve outcome 4 to outcome 0 . According to Russian preference sequence, outcome 0 has lower priority than outcome 6 . Therefore, since Ukraine is bound to resist, outcome 6 is stable for Russia. This resistance is inevitable, because it stands to reason that Ukraine will unilaterally improve outcome 4 to outcome 0 . In practical crisis, it is shown that Russia will not relax its actions of supporting agents in Crimea and eastern Ukraine in case of Ukrainian admission of Crimea independence, because Ukraine is likely to go back on its word without acknowledging Crimea independence. Similarly we can see that outcome 4 is stable for Ukraine.

Outcome 5,7,1,3,0,9,10,8 are unstable for Russia. Such as outcome 5, Russia has two unilateral improvements from outcome 5 to outcome 4 and outcome 6 which is known from Table 4 . Ukraine can unilaterally improve from 4 to 0 , and outcome 0 has lower priority than outcome 5 for Russia. Therefore, it is unreasonable for Russia to make a unilateral improvement from outcome 5 to outcome 
4. However, Russia will unilaterally improve unhindered from outcome 5 to outcome 6 if Russia want, because Ukraine has no unilateral improvement from outcome 6 . This shows that outcome 5 is stable for Russia. Similarly we can see that outcome 2,1,3,8,9,10,11 are unstable for Ukraine.

Outcome 1,3,8,9,10 are unstable for Russia and Ukraine, so it needs a test of synchronously restricted outcome. For example in Table 4, outcome 1 is unstable for Russia and Ukraine, Russia and Ukraine respectively make a unilateral improvement from outcome 1 to outcome 2 and outcome 5 . Therefore, Russian strategy should change (10) into (01), and Ukrainian strategy should change (00) into (10). Thus simultaneously improved outcome is (0110), which is actually outcome 6 . Outcome 6 has precedence over outcome 1 for Russia and Ukraine, so outcome 1 is still unstable for Russia and Ukraine. In other words, outcome 1 is not synchronously restricted outcome for both sides. Similarly we can see that outcome 3,8,9,10 are not synchronously restricted outcome for both sides.

If an outcome is stable for all the players, this outcome is an equilibrium solution, namely, one possible solution. All the remaining outcomes are not the equilibrium solutions. The equilibrium solutions are represented by $\mathrm{E}$, and then the non-equilibrium solutions are represented by $\mathrm{X}$. We can see that outcome 4 and outcome 6 are equilibrium solutions from last two lines of Table 4.

\section{Conclusions}

We should specifically analyze the status in quo of the crisis to determine which may be a possible solution from two equilibrium solutions. At the beginning of the crisis, Ukraine takes action to prevent the country from separation including internal chaos and ethnic divisions without Russian any action, which is equivalent to outcome 0 . Outcome 0 is reasonable for Ukraine, and then Russia will unilaterally improve outcome 0 to outcome 2 . Because outcome 2 is unstable for Ukraine, it will be unilaterally improved from outcome 2 to outcome 6 by Ukraine. Outcome 6 is an equilibrium solution which is the most possible solution. In other words, Russia will support Yanukovych as an agent in case of sending troops to ensure no damage to Russian allies, then Ukraine give up the ownership of Crimea and admit the independence of Crimea.

\section{References}

[1] Zuiliang Zhang. Military Operations Research [M]. Military Science Press, Beijing. 1993 : 584-597.

[2] Zuiliang Zhang. Military Strategic Operations Research Analysis [M]. Military Science Press, Beijing.2009.

[3] Decai Wang. Army NBC Protection Operations Research Analysis [M]. National Defense University Press, Beijing.2009 : 32-55.

[4] Qiyue Cheng. Command Decision Logistics Analysis [M]. Military Science Press, Beijing.2004. 